\title{
QUAL FAMÍLIA? A propósito do estudo social das famílias dos beneficiários
}

\author{
do Benefício de Prestação Continuada - BPC
}

Ademir Alves da Silva ${ }^{1}$

\section{RESUMO}

Tendo em vista a exigência de estudo social das famílias, para fins de concessão, manutenção ou suspensão do BPC - Benefício de Prestação Continuada, o presente texto trata da relação entre titularidade individual do "benefício" e sua restrição às pessoas cujas famílias apresentam renda per capta limitada contido na legislação social brasileira em contraposição às tendências quanto aos arranjos sócio afetivos que ensejam novos "modelos" de família em face da tradicional e dominante forma de organização familiar.

PALAVRAS-CHAVE: Família, Benefício de Prestação Continuada, Assistência Social

As reflexões aqui registradas foram instigadas pela questão da centralidade da família nos programas, projetos, serviços e benefícios da área da Assistência Social, conforme apontado nos Planos Regionais de Assistência Social - 2004, da cidade de São Paulo.

Os direitos sociais devem ser assegurados ao cidadão, sem qualquer exigência de que o mesmo componha, de modo permanente, uma unidade familiar ou viva "em família”.

1 Doutor em Serviço Social e Políticas Sociais pela PUC- SP, Professor nos Cursos de Serviço Social e de Relações Internacionais da PUC São Paulo e Assistente Social no Centro de Referência de Cidadania do Idoso da Secretaria Municipal de Assistência e Desenvolvimento Social de São Paulo. 
Todavia, a legislação social brasileira além de definir a responsabilidade da família pela proteção aos seus membros, vincula a concessão de benefícios à comprovação da renda familiar como ocorre, por exemplo, com o benefício de prestação continuada que se restringe às pessoas cujas famílias apresentem renda per capita limitada a $1 \frac{1}{4}$ do salário mínimo.

Ora, a cidadania se exerce pela mediação de instituições. Não há possibilidade de pleno exercício da cidadania senão por meio de formas associativas, organizativas, representativas e referenciais para os cidadãos. Em outros termos, a cidadania se expressa pela mediação de instituições criadas exatamente para assegurar as condições para a sua efetiva vigência. E a família é a instituição mais elementar da sociedade.

Ninguém é obrigado a "viver em família" e, muito menos, sob um matrimônio. O cidadão pode decidir - e preferir - não constituir nova família, no sentido de procriação ou reprodução. Pode recusar, pode fazer a crítica, pode até renegar seus ancestrais, pode romper relações com sua família, mas não pode abstrair-se do pertencimento a uma família de origem, enquanto núcleo de reprodução. Uma condição não apenas dele, indivíduo. Mas da espécie humana.

Ou seja, a família - rede primária de relações - é, inelutavelmente, uma instituição fundamental da vida em sociedade. A despeito de prestar-se a sustentar concepções conservadoras de família e de ordem social, a noção de célula mater, ao expressar uma condição básica da vida social, parece insistir em manter sua aplicabilidade na sociedade contemporânea, a despeito da recorrente "crise da família" ou, o que seria mais apropriado conceber, crise de determinado modelo dominante de família. 
A reflexão sobre a família pode nos conduzir a processos emancipatórios e de exercício pleno das capacidades humanas, mas pode também revelar-nos reféns de nós mesmos, pelas questões que envolve: o afeto e o desafeto, o amor e o desamor, a fidelidade e a traição, as alianças e as rupturas, as boas e as más lembranças, os ressentimentos, a culpa, o passado, o presente e o futuro. Projetos bem-sucedidos ou projetos inacabados, inconclusos, jamais realizados.

Família é memória. E não no sentido de algo fossilizado, um passado congelado. Mas, memória em movimento. Ao mesmo tempo em que rememoro, faço avaliações e projeções. Memória, enquanto legado e utopia. Recordações e lembranças, justamente porque podem ser boas ou más, remetem a projeções: Faria tudo outra vez, se preciso fosse! Ou: Errar é humano, permanecer no erro é burrice! Ou: Onde estava com a cabeça? - para utilizar aqui algumas expressões populares.

A questão é: qual família?

Nem todo enlace sócio afetivo conduz à constituição de uma família. Mas, é fato que toda família - obviamente não estou me referindo ao estupro - nasce de algum envolvimento afetivo ou amoroso que dificilmente poderia ser reduzido à "conjunção carnal". A não ser pelas chamadas "produções independentes", mas que supõem, necessariamente, um affair, um acordo em torno de determinadas condições mínimas para uma relação sexual.

É certo que a reprodução assistida deslocou - do "leito", do "lar" ou de onde quer que se tenham feito ${ }^{2}$ filhos até hoje - para o laboratório a concepção e a geração de seres humanos, em torno de inúmeras alternativas que passam pela paternidade anônima, 
pela doação de sêmem, a fertilização in vitro, a inseminação artificial, a subrogater mother (barriga de aluguel).

De qualquer modo, tudo isso se passa em torno do desejo - ou seria da necessidade? - de se ter uma família, ampliando-se para relações mais ou menos impessoais o circuito de sua reprodução.

Mas, não há razões para supor que o "crescei e multiplicai-vos" do Livro do Gênesis signifique, necessariamente, a constituição de família no sentido idealizado e dominante em que a conhecemos: burguesa, "tradicional" ou do tipo da propaganda da margarina. Está aí uma questão que remete à discussão de um elenco de princípios e valores e, portanto, critérios de diferença, de preferência, de escolha e de opção, respeitada a autonomia individual, o que não significa a recusa de determinados valores historicamente pactuados como universais, no âmbito dos direitos humanos.

A chamada família tradicional jamais conseguiu responder pela fidelidade ao modelo que fez de si mesma, marcada pelas contradições inerentes à "alma humana": o moral e o imoral, a honra e a desonra, o decente e o indecente, a virtude e o vício, o orgulho e a vergonha, etc.

A literatura brasileira, especialmente a rodrigueana, e a universal são pródigas em retratar em inúmeros Álbuns de Família os dramas e as tragédias das famílias edipiana, shakespeareana, freudiana, provinciana, mineira, tradicional, quatrocentona, burguesa e operária. 


\section{A FAMÍLIA NA LEGISLAÇÃO:}

A Constituição Federal, em seu artigo 226, estabelece: “A família, base da sociedade, tem especial proteção do Estado. Parágrafo $3^{\circ}$ - Para efeito de proteção do Estado, é reconhecida a união estável entre o homem e a mulher como entidade familiar, devendo a lei facilitar sua conversão em casamento. Parágrafo $4^{o}$ - Entende-se, também, como entidade familiar a comunidade formada por qualquer dos pais e seus descendentes. Parágrafo $5^{\circ}$ - Os direitos e deveres referentes à sociedade conjugal são exercidos igualmente pelo homem e pela mulher [...] Parágrafo $8^{\circ}$ - O Estado assegurará a assistência à família na pessoa de cada um dos que a integram, criando mecanismos para coibir a violência no âmbito de suas relações"

Segundo a Lei 9278 de 10/05/96, artigo 1', "É reconhecida como entidade familiar a convivência duradoura, pública e contínua de um homem e uma mulher, estabelecida com objetivo de constituição de família".

Segundo a Lei 9720 de 30/11/98, "entende-se como família o conjunto de pessoas elencadas no artigo 16 da Lei $n .8213$ de 24/07/91, desde que vivam sob o mesmo teto.

Esta última lei estabelece, em seu artigo 16, que "são beneficiários do Regime Geral da Previdência Social, na condição de dependentes do segurado: I - o cônjuge, a companheira, o companheiro e o filho, de qualquer condição, menor de 21 anos ou inválido; II - os pais; III - o irmão, de qualquer condição, menor de 21 anos ou inválido; IV - a pessoa designada, menor de 21 anos ou maior de 60 anos ou inválida.

$1^{\circ}$ A existência de dependente de qualquer das classes deste artigo exclui do direito às prestações os das classes seguintes.

$2^{\circ}$. Equiparam-se a filho, nas condições do inciso I, mediante declaração do segurado: o enteado, o menor que, por determinação judicial, esteja sob a sua guarda; e o menor que esteja sob sua tutela e não possua condições suficientes para o próprio sustento e educação.

$3^{\circ}$ Considera-se companheira ou companheiro a pessoa que, sem ser casada, mantém união estável com o segurado ou com a segurada, de acordo com o parágrafo $3^{\circ}$ do art. 226 da Constituição Federal.

$4^{\circ}$ A dependência econômica das pessoas indicadas no inciso I é presumida e a das demais deve ser comprovada"

Segundo a Lei 8069 de 13/07/90, artigo 25: “Entende-se por família natural a comunidade formada pelos pais ou qualquer deles e seus descendentes. Artigo 26: Os filhos havidos fora do casamento poderão ser reconhecidos pelos pais, conjunta ou separadamente, no próprio termo de nascimento, por testamento, mediante escritura ou outro documento público, qualquer que seja a origem da filiação. Parágrafo único: $O$ reconhecimento pode preceder o nascimento do filho ou suceder-lhe ao falecimento, se deixar descendentes. Artigo 27. O reconhecimento do estado de filiação é direito personalíssimo, indisponível e imprescritivel, podendo ser exercido contra os pais ou seus herdeiros, sem qualquer restrição, observado o segredo de Justiça [...] Artigo 41. A adoção atribui a condição de filho ao adotado, com os mesmos direitos e deveres, inclusive sucessórios, desligando-o de qualquer vínculo com pais e parentes, salvo os impedimentos matrimoniais" 
São amplamente conhecidos os estudos clássicos ${ }^{3}$ sobre o papel da família - e de sua necessidade histórica - na preservação da propriedade privada e na constituição do próprio Estado, respondendo pela consolidação e manutenção da ordem social, política e econômica.

De fato, instituiu-se, pelo menos no lado ocidental do mundo, um modelo dominante de família com base no qual erigiu-se um complexo ordenamento jurídicoinstitucional em torno de questões como herança, relações de dependência em face do fisco e da previdência social e responsabilidades para com os filhos naturais ou adotivos.

A família sempre protagonizou papel decisivo na dinâmica da reprodução social. Jarvis \& Redmond (1997) apresentam interessante quadro comparativo de dois modelos de Estado de Bem-Estar Social, com destaque para a forma de conceber a família. No caso do Reino Unido, prevaleceu o modelo centrado na figura masculina do breadwinner (literalmente, ganhador do pão), no inglês, ou soutien de famille, no francês. Trata-se da família nuclear, dependente da renda do pai inserido no mercado de trabalho. A mulher restringia-se ao trabalho no lar, ocupando-se dos cuidados em relação aos filhos, sem recorrer à ajuda do Estado, sendo subordinada ao marido para fins de impostos, contribuições e benefícios.

Já no caso da Hungria vigorou até recentemente o modelo individual, em que cada integrante do casal é individualmente responsável por sua própria manutenção, havendo igual tratamento dos sexos no mercado de trabalho. A responsabilidade pelas crianças é compartilhada. A "unidade" para fins de impostos e benefícios é o indivíduo e não a família. E há um forte envolvimento do Estado nos cuidados dos dependentes.

3 Ver, a propósito: Engels, F. A origem da família, da propriedade privada e do Estado. Rio de Janeiro: Editora Civilização Brasileira, 1984, 9ª edição. 
É inegável que, a partir da segunda metade do século XX, a família vem passando por inúmeras transformações em direção a novos arranjos sócio afetivos, estratégias de sobrevivência ou acordos em torno da criação de filhos. Escolhas que dependeram, certamente, de grande conteúdo de insurgência e de transgressão em face de valores dominantes, além das determinações socioeconômicas.

No Brasil recente, ampliou-se o protagonismo feminino em todos os setores da vida social, particularmente no mercado de trabalho. A unidade familiar sob comando da figura paterna vem dando lugar ao maior intercâmbio de papéis de ambos os sexos na gestão familiar, sendo crescente a frequência de famílias monoparentais em que a mulher responde, sozinha, pela manutenção do grupo familiar, e não apenas nas camadas sociais subalternizadas. A Constituição Federal garante a proteção do Estado à entidade familiar resultante do casamento ou da união estável entre homem e mulher. A Lei 9278/96 define entidade familiar como a convivência duradoura, pública e contínua, de um homem e uma mulher, visando a formação de uma família. Homem e mulher estão em igualdade de condições respondendo, ambos, por todas as necessidades da família, especialmente os cuidados em relação aos filhos.

Segundo Silvia Pimentel "o novo Código Civil representa um grande avanço, especialmente no que diz respeito à igualdade de direitos de homens e mulheres (...) Introduz, expressamente, conceitos como os de direção compartilhada (em vez de chefia masculina da sociedade conjugal) e de poder familiar compartilhado (no lugar da prevalência paterna do pátrio poder); também inova, entre outros aspectos, ao substituir o termo "homem", quando usado genericamente para referir ao ser humano, pela palavra "pessoa", ao permitir ao marido adotar o sobrenome da mulher e ao estabelecer que a guarda dos filhos passa a ser do cônjuge com melhores condições de exerce-la".

4 Pimentel, S. O novo Código Civil e a Igualdade. In Jornal do CRESS-SP n. 41, jan./mar./2003. 


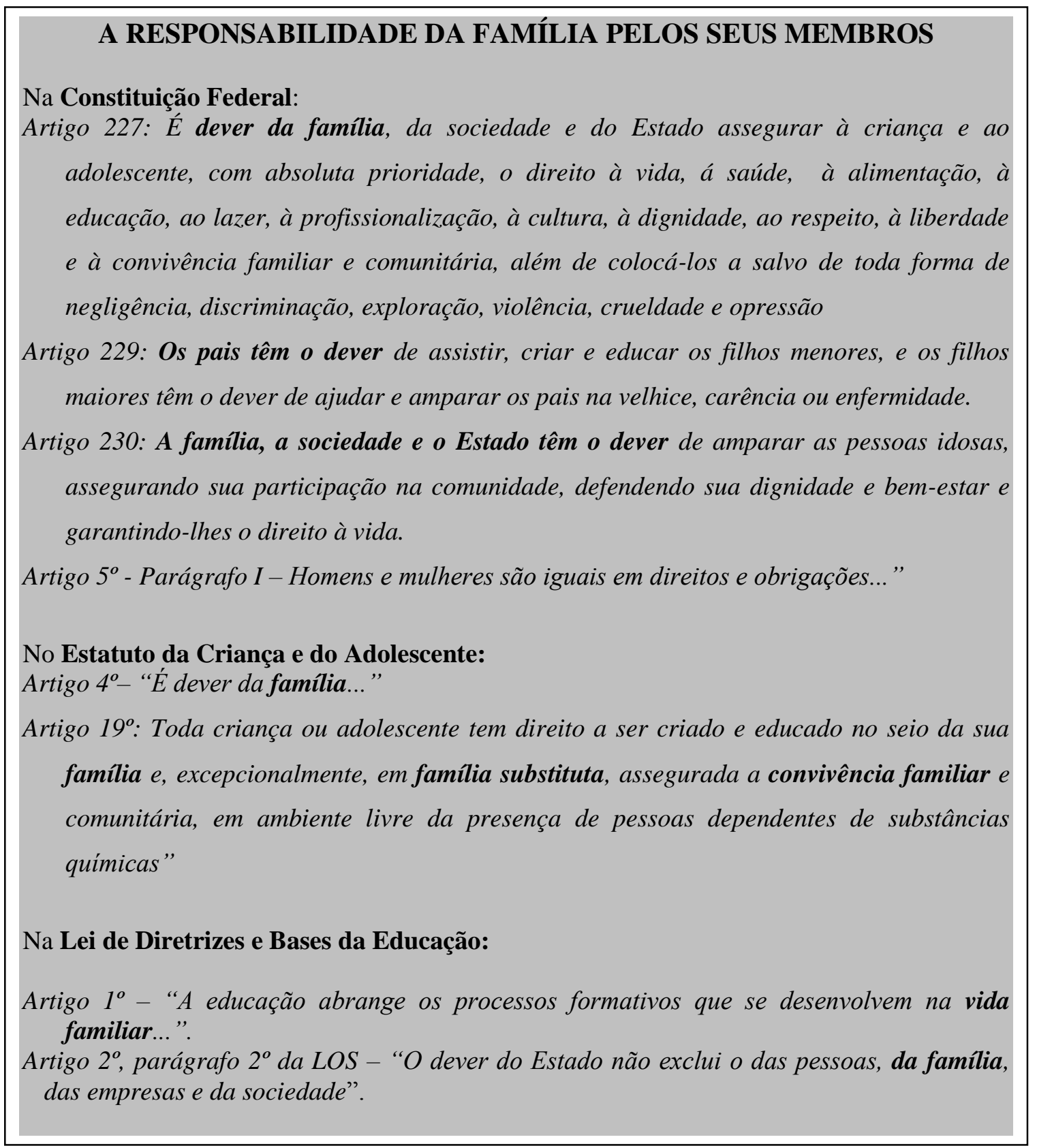

Na prática, a família sempre foi uma oficina de relações sociais, uma espécie de laboratório da vida em sociedade, reproduzindo ou pondo em questão em seu âmbito, processos históricos mais amplos que a circunscrevem e determinam. 
Assim é que se dão as opções pela criação efetivamente compartilhada dos filhos, por não ter filhos, por reduzir o número de filhos, por manter relações amorosas vivendo separados, por promover uniões homossexuais também com adoção de filhos ${ }^{5}$, por arranjos sócio afetivos alternativos, por viver juntos sem ser legalmente casados, por casar-se legalmente por razões econômicas, por uniões menos duradouras e sucessivas, por viver só e desacompanhado, por viver em grupos, por não pretender constituir família, etc.

Os profissionais da área social - outros também - utilizam largamente as expressões "família desestruturada", "família desajustada" ou "família desorganizada" para referirem-se a inúmeros problemas sociais que se manifestam no âmbito das famílias usuárias dos serviços sociais, públicos e/ou privados. Está aí uma posição ingênua, equivocada ou ideologicamente filiada a uma concepção de família, tributária do modelo dominante tomado, a priori, como o melhor, o mais adequado ou o desejável para todos.

O que é tratado como família desajustada é, frequentemente, a expressão de arranjos ou estratégias defensivos em face das ameaças, privações e adversidades cotidianas. Então, o "nóis véve do jeito que Deus é servido" - no caso das camadas populares subalternizadas - não é de todo uma manifestação de conformismo em face de condições que seriam inevitáveis ou fatais, mas pode significar viva resistência, processada adaptação ou, o que é lamentavelmente frequente, derrota na luta pela vida. Resistem, no entanto, os componentes de um projeto familiar.

5 Após a morte de Cássia Eller, a disputa relacionada à reivindicação - pelos avós maternos e pela companheira da cantora - de responsabilidade pelo seu filho, reacendeu a polêmica quanto às uniões homossexuais com ou sem filhos havidos de união anterior ou adotivos. Estima-se em 1 milhão o número de gays, lésbicas, bissexuais e transexuais em São Paulo. A par do crescimento declarado e assumido do segmento de GLBT, intensificam-se as pressões pela legalização de uniões civis de homossexuais, podendo levar ou não à criação compartilhada de filhos. 


\section{O BPC NA LEGISLAÇÃO:}

Um dos objetivos da Assistência Social é, segundo o artigo 203, inciso V, da Constituição Brasileira: "a garantia de um salário mínimo de benefício mensal à pessoa portadora de deficiência e ao idoso que comprovem não possuir meios de prover a própria manutenção ou de te-la provida por sua família, conforme dispuser a lei"

A LOAS dispõe, em seu artigo 20, que: "Artigo 20: O benefício de prestação continuada é a garantia de 1 (um) salário mínimo mensal à pessoa portadora de deficiência e ao idoso com 70 (setenta) anos ou mais e que comprovem não possuir meios de prover a própria manutenção e nem de tê-la provida por sua família"

"Parágrafo $3^{\circ}$ Considera-se incapaz de prover a manutenção da pessoa portadora de deficiência ou idosa a família cuja renda mensal per capita seja inferior a 1/4 do salário mínimo.

Artigo 38 - A idade prevista no art. 20 desta Lei reduzir-se-á para sessenta e sete anos a partir de $1^{\circ}$ de janeiro de 1998" (De acordo com a Lei 9.720 de 30/11/98)

Já o Estatuto do Idoso - Lei 10.741 de 01/10/03, estabelece em seu artigo 34 que: “Aos idosos, a partir de 65 anos, que não possuam meios para prover sua subsistência, nem de tê-la provida por sua família, é assegurado o benefício mensal de 1 salário mínimo, nos termos da LOAS.

Parágrafo único: $O$ benefício já concedido a qualquer membro da família nos termos do caput não será computado para os fins do cálculo da renda familiar per capita a que se refere a LOAS". Mas, o mesmo Estatuto, em seu artigo 117, dispõe que "O poder executivo encaminhará ao Congresso Nacional projeto de lei revendo os critérios de concessão do Benefício de Prestação Continuada previsto na LOAS, de forma a garantir que o acesso ao direito seja condizente com o estágio de desenvolvimento socioeconômico alcançado pelo País" 
Inúmeras pesquisas apontam o crescente protagonismo da mulher na "chefia de lares". É certo que se dissolve a família nuclear usual - pela presença de pai, mãe e filhos - mas persiste o núcleo familiar ainda que monoparental e matrifocal definido, de qualquer modo, pelo vínculo consanguíneo ou de parentesco. ${ }^{6}$

Nos eventos e documentos da área de Assistência Social reitera-se à exaustão o "foco na família", a "centralidade da família", a necessidade de "apoio à família" quando se pretende proteger a criança e o adolescente, por exemplo. ${ }^{7}$

Destarte, na discussão sobre a pertinência ou não de se tomar a família e não o indivíduo - pessoa idosa ou pessoa com deficiência - como foco dos estudos sociais para informar decisão judicial quanto à concessão do BPC - Benefício de Prestação Continuada, impõe-se a consideração de que, embora o demandante legítimo do benefício seja o cidadão individual, sua demanda expressa-se, invariavelmente, pela mediação de uma unidade familiar $^{8}$, com exceção dos idosos que vivem sós por opção, por necessidade ou mesmo por abandono. E a pessoa com deficiência - admitidos variados graus e situações de dependência em relação a outras pessoas - ainda tem, predominantemente, dentre os familiares a figura do cuidador, especialmente a mulher,

\footnotetext{
6 Nas discussões mais recentes em torno de demandas relacionadas à implantação de serviços voltados para mulheres é recorrente a preocupação em acrescentar "com filhos".

7 A SEAS - Secretaria de Estado de Assistência Social, do governo FHC, implantou o Programa dos NAF - Núcleos de Apoio à Família. O Ministério de Assistência Social, do governo Lula, vem formulando o Programa de Atendimento Integral à Família - PAIF. A própria SAS - Secretaria Municipal de Assistência Social de São Paulo respondeu, nos anos de 2002 e 2003, pela municipalização do Programa Fortalecendo a Família, ao firmar convênio com o Governo do Estado e com a PUC-SP para atendimento a 14 mil famílias. A partir dessa experiência implantou, em janeiro/2004, o PROASF - Programa de Assistência Social a Famílias. E vem formulando o Programa Família Guardiã , em conformidade com o artigo $28^{\circ}$ do ECA, que estabelece que a "colocação em família substituta far-se-á mediante guarda, tutela ou adoção, independentemente da situação jurídica da criança ou adolescente...”. A Secretaria de Assistência Social de Campinas vem se empenhando em encontrar alternativas para uma aproximação entre as famílias substituta e natural, de modo a favorecer o desenvolvimento da criança, observando-se o princípio do convívio familiar e comunitário. Realizou-se em novembro de 2003, em Porto Alegre, um Encontro dos Conselhos Tutelares da região Sul, sob o tema central: "Mais família"

8 Em minha experiência profissional, pelo atendimento no CRAS da SAS-Vila Mariana, por cerca de 2 anos, foi possível conhecer inúmeros casos de mulheres idosas respondendo pelos cuidados de "famílias" (a filha separada e netos, o genro desempregado, etc) embora dispondo apenas do BPC e de ganhos esporádicos dos "bicos" praticados pelos mais jovens integrantes da unidade familiar.
} 
conforme o caso.

Então, a despeito da titularidade - pelo cidadão individual - do benefício, tanto mais consistente será o estudo social de sua petição, quanto mais for capaz de situar a demanda em questão no contexto da rede de relações familiares circunscritas às relações sociais, políticas, econômicas e culturais que as determinam.

Não se trata, portanto, de alimentar a tendência restauradora da concepção conservadora de família, restringindo à mesma o ônus quanto à proteção social de seus membros, como se o risco fosse algo restrito à esfera individual ou do âmbito da família.

Nem, tampouco, de corroborar a estratégia da contrarreforma do Estado, que desobriga a esfera pública quanto à responsabilidade indelegável pela garantia de condições - na esfera pública - para o pleno exercício da cidadania, reeditando a concepção - de resto, profundamente arraigada em nossa cultura - de que a família "que se vire" na responsabilidade pelos "seus" doentes, anciãos, deficientes, incapacitados para o trabalho, onerando os segmentos sociais subalternizados e os trabalhadores em geral na esfera do trabalho e do consumo - e desonerando o capital e os detentores das maiores parcelas da riqueza social.

Trata-se, isso sim, de por em questão as possibilidades de organização familiar na sociedade contemporânea, indagando quanto ao seu papel na dinâmica da reprodução social. Ou seja, a família entendida como parte da totalidade social histórica, o que equivale dizer, indissociável do Estado, do mercado, do conjunto da sociedade. 
A noção de renda familiar é decisiva, embora insuficiente na avaliação da condição socioeconômica das famílias. Uma condição que depende, obviamente, de um conjunto de fatores que extrapolam a renda mensal total ou per capita. No caso do BPC, é evidente que o que está em questão não é a família provedora ou incapaz de prover, mas o uso que se faz dela para rebaixar o valor do benefício quando a LOAS estabelece "renda per capita limitada a 1/4 do salário mínimo", exigindo que o pleiteante comprove uma condição social miserável para credenciar-se ao mísero benefício.

Ou seja, a questão não está em se tomar a família ou mesmo a renda familiar como referência. A questão remete, inelutavelmente, à iníqua distribuição da renda nacional, à imoralidade do salário mínimo, à ainda reduzida cobertura dos benefícios da seguridade social, aos ainda restritos programas de transferência de renda, à imposição às famílias do ônus - individualizado - pela própria manutenção.

\begin{abstract}
This article deals with the social family study, requirement for concession, maintenance or interruption of BPC - Benefício de Prestação (Continuous Rendering Benefit). It is about the relationship with the individual claim and the restriction to families that present per capita income limited to $1 / 4$ of the minimum wage. This paper also deals with the concept of family in the Brazilian legislation, tendency toward news models of social affection families against the traditional and dominant family organization.
\end{abstract}

KEYWORDS: Family, Social Assistant, Continuous Rendering Benefit 


\section{REFERÊNCIAS BIBLIOGRÁFICAS}

ENGELS, F. A origem da família, da propriedade privada e o do Estado. Rio de Janeiro: Editora Civilização Brasileira, 1984.

PIMENTEL, S. O novo Código Civil e a Igualdade. In: Jornal do CRESS-SP, n. 41, $\mathrm{jan} / \mathrm{mar} / 2003$.

BRASIL: Legislação

CONSTITUIÇÃO FEDERAL, 1988

Lei n. 8742 de 07/12/93 - Lei Orgânica de Assistência Social

Lei n. 9394/96 - Lei de Diretrizes e Bases da Educação Nacional

Lei n. 8069 de 13/07/90 - Estatuto da Criança e do Adolescente

Lei n. 10.741 de 01/10/03 - Estatuto do Idoso

Lei 9278 de 10/05/96 - União Estável

Lei 9720 de 30/11/98 - Alteração de dispositivos referentes ao BPC da Lei 8742/93 